\title{
Trabalho médico e gestão de Saúde
}

Juan S. Yazlle Rocha ${ }^{1}$

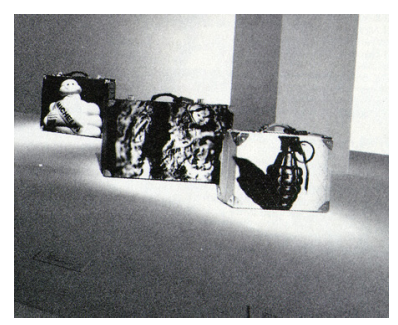

O texto Um ensaio sobre o médico e suas valises tecnológicas: contribuições para compreender as reestruturações produtivas do setor saúde trata de um problema atual e brasileiro: o ingresso de empresas financeiras nacionais (e a pressão das estrangeiras) no mercado dos Planos de Saúde e as transformações que acarretam ao trabalho médico, principalmente a disputa interna entre interesses capitalistas no setor saúde. Valese da imagem da valise do médico, que tipifica em três: aquela tradicional que transporta instrumentos, outra que "carrega" o saber do profissional $e$ uma terceira que compreende o espaço relacional trabalhador-usuário ... implicada com a produção das relações entre ambos. Neste espaço ocorreriam as capturas por diferentes lógicas sociais, que procuram tornar a produção das ações de saúde de acordo com certos interesses e interditar outros. Os diferentes arranjos entre valises é que determinariam os modelos de atenção à saúde. A finalidade do trabalho médico ficaria à mercê de um jogo de capturas entre usuários e diferentes interesses. $O$ trabalho médico possuiria duas dimensões básicas: a propriamente cuidadora - presente em todos os tipos de trabalho - e a profissional, com recorte tecnológico específico. Acredita que o trabalho médico procura capturar o usuário e seu mundo ... para dentro do seu agir tecnológico e... subsumi-lo a este. A terceira valise, das tecnologias leves, foi subsumida neste processo por uma relação privilegiada das outras duas, e o trabalho vivo em ato do médico tende a ser plenamente capturado e expresso por saberes tecnológicos que reduzem seu foco de ação à produção dos procedimentos. As tensões produzidas pelo modelo levam à procura constante de um perfil profissional generalista e de modalidades assistenciais de baixo custo que, todavia, ao não romperem com o modelo não promovem a eficácia e efetividade mas viriam ao encontro da tendência consumista dos usuários. Outra tendência de solução da crise seria representada por modalidades do capital que mediante tecnologias específicas tentariam capturar a microdecisão clínica por uma gerencial.

\footnotetext{
${ }^{1}$ Professor do Departamento de Medicina Social, Faculdade de Medicina de Ribeirão Preto, USP.
} 
Assegura que o capital financeiro de setores neoliberais disputa atividades lucrativas e promove modelos de controles de custos dos projetos terapêuticos, para tanto introduzindo a noção de "acidentalidade", e que ferramentas da economia geram projetos de prevenção de riscos incorporando noções da Epidemiologia. São projetos de Home-Care, de adscrição de clientela procurando capturar a microdecisão médica por uma microdecisão gerencial comandada pelo capital financeiro. Neste movimento de mobilização do capital pelo mundo inclui-se o Managed Care. Assim, teríamos uma transição tecnológica e uma reestruturação produtiva do setor capitaneada pelo capital financeiro.

Há uma sólida tradição de estudos acerca do trabalho na sociedade capitalista, iniciada por Marx, e do trabalho médico em particular: Polack, Donnangelo, García, Arouca, Mendes Gonçalves. $\mathrm{O}$ trabalho de Merhy segue em parte esta tradição, acerta em alguns problemas que levanta e complica a análise pelo uso livre de termos e conceitos. Assim, se é fácil aceitar a imagem das duas primeiras valises isto não ocorre com a terceira: o espaço relacional trabalhadorusuário ... não é uma valise do médico mas é um espaço social - marcado por relações de classes - e não uma valise instrumental do médico ou de qualquer outro trabalhador. A pergunta fundamental que Merhy se propõe discutir é: Como se determina o trabalho médico hoje? Para elucidar esta questão seria preciso ir além da análise dos instrumentos (as valises). Vale lembrar que o reconhecimento como trabalho implica em admitir a existência de uma contrainte, interna ou externa às próprias atividades, que as diferenciam das atividades livres - artes ou ciência. Outra dificuldade no trabalho é um certo mecanicismo presente nas idéias das capturas: ora o sujeito capturante é a lógica produtiva inserida nos equipamentos ou na tecnologia, ora é o paciente, ora é o capital, ora é o médico a capturar as necessidades e o mundo do paciente - sem aclarar a sua natureza. Como tecnologias específicas poderiam "capturar" microdecisões clínicas por uma gerencial? Parece-nos que o verbo é utilizado com várias acepções, o que dificulta a compreensão da análise. Centrado na análise dos instrumentos do trabalho médico, tece ilações sobre as influências que se exercem sobre o mesmo; todavia, os outros elementos definidores do trabalho, como a finalidade perseguida, a concepção do objeto, o tipo de relação entre o agente e seu objeto, não estão incluídos. Não é correta a afirmação que o trabalho médico procura capturar o usuário e seu mundo para dentro do seu agir tecnológico e subsumí-lo a este; ao contrário, como Mendes Gonçalves demonstrou, o projeto médico é definido socialmente e a Medicina o toma como objeto da sua prática. É assim que ela contribui para a produção de condições materiais e não-materiais inerentes à reprodução ampliada do(s) modo(s) de produção. (Mendes Gonçalves, 1979). Por isso, ao contrário do que parece, a Medicina não é vitima unilateral neste processo social de transformações mas, por efeito dessa mesma determinação estrutural se constitui ela própria em sujeito que contribui para a recriação sob nova forma das estruturas... que a presidem (Mendes Gonçalves, 1979). O trabalho médico no Brasil sofre hoje as conseqüências 
da interferência do capital, já conhecidas desde Taylor e descritas por Braverman (1980) para o trabalho em geral: "O modo capitalista de produção destrói sistematicamente todas as perícias à sua volta, e dá nascimento a qualificações e ocupações que correspondem às suas necessidades... A distribuição generalizada do conhecimento do processo produtivo... torna-se... não meramente "desnecessária" mas uma barreira concreta ao funcionamento do modo capitalista de produção". Taylor elevou o conceito de controle a um plano inteiramente novo quando asseverou como uma necessidade absoluta para a gerência adequada a imposição ao trabalhador da maneira rigorosa pela qual o trabalho deve ser executado.

Outros modelos de prestação de serviços têm aparecido entre nós e nos países industrializados. Para fugir aos problemas ocasionados pela Medicina do capital e sua gerência "científica", temos a emergência de modelos gerenciais e de prestação de serviços baseados na organização autônoma da comunidade, dos prestadores, dos trabalhadores etc. Procura-se, também, formas de financiamento baseadas não no pagamento de serviços prestados mas na gestão do sistema com remuneração per capita; procura-se a eficiência do sistema na prevenção - ou gestão do risco e assim são resgatados modelos de cuidados a domicílio ou da saúde da família, por serem mais eficientes, além de menos custosos. A Organização Mundial de Saúde, OMS, admite oficialmente que os melhores sistemas de saúde são aqueles que contam com financiamento público $e$ prestação pública $e$ privada de serviços, sob controle social. Ainda assim, o problema dos custos assola todos os sistemas de saúde do mundo ao ponto que a OMS propõe, para as primeiras décadas do novo milênio, rever o conceito do direito universal à saúde, trocado por outro de direito limitado ou relativo (WHO, 1999).

Finalmente, mais do que uma transição tecnológica e reestruturação produtiva apenas, o que temos é uma grande transformação da sociedade, que vai enterrando tradições e modificando nossa forma de viver e atuar; a Medicina e os serviços de saúde começam a passar por esse processo de (re)construção do novo.

\section{Referências bibliográficas}

BRAVERMAN, H. Trabalho e capital monopolista: a degradação do trabalho no século XX. Rio de Janeiro: Zahar, 1980.

MENDES GONÇALVES, R.B. Medicina e história: raízes sociais do trabalho médico. São Paulo, 1979. Dissertação (Mestrado). Faculdade de Medicina da Universidade de São Paulo, FMUSP. WHO. World Health Report, 1999. Geneva: WHO, 1999.

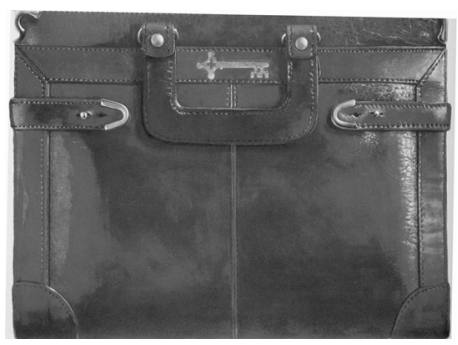

